\title{
DISTRIBUIÇÃO DE LARVAS DE NEMATÓDEOS GASTRINTESTINAIS DE OVINOS EM PASTAGENS DE INVERNO
}

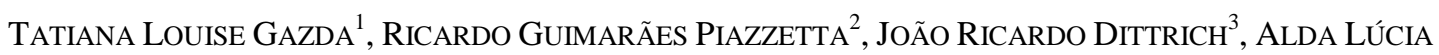 \\ GOMES MONTEIRO ${ }^{4}$, VANETE THOMAZ SOCCOL ${ }^{5}$ \\ ${ }^{1}$ Mestre em Ciências Veterinárias, Universidade Federal do Paraná, Curitiba, PR, Brasil. tatiloui@ gmail.com \\ ${ }^{2}$ Mestre em Ciências Veterinárias, Universidade Federal do Paraná, Curitiba, PR, Brasil \\ ${ }^{3}$ Professor Doutor, Universidade Federal do Paraná, Curitiba, PR, Brasil \\ ${ }^{4}$ Professora Doutora, Universidade Federal do Paraná, Curitiba, PR, Brasil \\ ${ }^{5}$ Universidade Positivo, 'Pró Reitoria de Pós Graduação. Curitiba, PR, Brasil
}

As infecções parasitárias são de ocorrência bastante preocupante nos sistemas de produção de ovinos em pastagens. Assim, este trabalho foi realizado com o objetivo de conhecer a dinâmica das larvas de nematódeos parasitos de ovinos em pastagens de inverno. $\mathrm{O}$ delineamento utilizado foi inteiramente casualizado. Os tratamentos foram compostos por duas diferentes ofertas de matéria seca de duas espécies forrageiras (aveia preta $5 \%$ e $12 \%$; azevém $10 \%$ e $20 \%$ ), totalizando quatro tratamentos. Os animais traçadores utilizados foram 28 borregas da raça Suffolk. A cada quinze dias foram coletadas amostras de pastagem dos piquetes, estratificadas em fração superior e inferior da pastagem para contagem e identificação de larvas de nematódeos. Os animais foram acompanhados quinzenalmente por meio de exames coproparasitológicos. $\mathrm{Na}$ pastagem de azevém, verificou-se maior contaminação por larvas de helmintos por grama de matéria seca $(104,53 \mathrm{~L} / \mathrm{g} \mathrm{MS})$ $(\mathrm{p}<0,05)$ do que na de aveia $(24,6 \mathrm{~L} / \mathrm{g} \mathrm{MS})$. Houve aumento linear com o tempo no número de larvas de helmintos por grama de matéria seca no estrato pastejado da pastagem de aveia em menor oferta de forragem. Os animais mantidos em diferentes ofertas de forragem de aveia e azevém não apresentaram diferença em relação à carga parasitária $(\mathrm{p}>0,05)$. Entretanto, observou-se aumento linear com o tempo no número de ovos de helmintos por grama de fezes dos animais em pastagem de aveia com menor oferta. Os resultados confirmaram que a alta carga animal por unidade de área contribuiu para a contaminação constante da pastagem e consequentemente para a infecção dos animais.

PALAVRAS-CHAVE: nematódeos gastrintestinais; ovinos; pastagens; Trichostrongylidae.

\section{DISTRIBUTION OF GASTROINTESTINAL NEMATODE LARVAE OF SHEEP ON WINTER PASTURE}

\section{ABSTRACT}

The aim of this work was to study the dynamics of nematode larvae of sheep on winter pasture species. A completely randomized design was used. The treatments were composed by two different dry matter offers of each forage species (black oat $5 \%$ and $12 \%$; ryegrass $10 \%$ and $20 \%$ ). A total of 28 Suffolk female lambs were used. Pasture was taken every fifteen days and samples were separated into superior and inferior fractions and sent for counting and identification of parasite larvae. Lambs were evaluated each fifteen days for parasitological evaluations Ryegrass (104.53 L/g MS) presented higher $(\mathrm{p}<0.05)$ contamination by helminth larvae per dry matter gram (L/g MS) than black oat forage (24.6 L/g MS). A linear increase in the amount of helminth larvae per gram of dry matter in the superior part of the plant was observed in black oat with lower dry matter content. The animals maintained in different dry matter offers of ryegrass and black oat did not present difference $(\mathrm{p}>0.05)$ in the worm 
burden. Otherwise a trend of linear increase in the number of fecal egg count was observed in the treatment with black oat with lower dry matter content. Sheep rearing in high stocking rates leads to parasitic infection of animals and environment contamination by pathogenic helminth larvae.

KEYWORDS: gastrointestinal nematodes; pasture; sheep; Trichostrongylidae.

\section{INTRODUÇÃO}

Parasitos gastrintestinais representam grande obstáculo à ovinocultura e fazem com que o resultado produtivo seja reduzido e se apresente muito aquém ao potencial da espécie. A verminose, um dos principais problemas da ovinocultura, devese principalmente às características de criação: animais criados em pequenas áreas e com superlotação, levam a um número elevado de larvas de helmintos nas pastagens, que, por sua vez, atuam como fonte de infecção constante. Diversos ovinocultores, para controlar o problema de verminose, adotam esquema de desverminações múltiplas ou supressivas; o resultado corresponde a um alto custo de tratamento e ao rápido desenvolvimento de resistência dos parasitos aos vários princípios ativos (THOMAZ-SOCCOL et al., 1996; THOMAZ-SOCCOL et al., 2004).

A eficiência do controle dos helmintos gastrintestinais está intrinsecamente ligada à dinâmica populacional dos parasitos dentro e fora do hospedeiro, havendo necessidade de se identificar o comportamento das fases larvais de helmintos em espécies forrageiras diversas, com ofertas de forragem variadas, em diferentes estações do ano. A estimativa do número de larvas infectantes de tricostrongilídeos na pastagem é parte integrante do estudo da ecologia e da epidemiologia desses nematódeos parasitos de ruminantes (CASTRO et al., 2003). NIEZEN et al. (1998a) e NIEZEN et al. (1998b) relataram que animais em diferentes tipos de pastagens não apresentam os mesmos níveis de infecção por helmintos gastrintestinais.

$\mathrm{O}$ uso integrado de práticas de manejo de pastagens associadas ao uso profilático dos antihelmínticos é importante para que se obtenha sucesso na produção intensiva de ovinos a pasto. REINECKE (1994) afirmou que alternativas devem ser estudadas, visto que a infecção de ovinos por parasitos gastrintestinais pode ser fator determinante da inviabilidade da criação intensiva de ovinos em pastagens. Na alimentação de ovinos em pastagens, recomenda-se de 7 a $10 \%$ do peso vivo dos animais de oferta de matéria seca de forragem (MORAES e MARASCHIN, 1988). No entanto, na prática, é comum se observar produtores que mantêm seus animais em pastagens que ofertam $5 \%$, ou até porcentagem inferior, de matéria seca em relação ao peso vivo dos animais sem qualquer tipo de suplementação nutricional.

O presente trabalho foi realizado em busca de se conhecer o comportamento das larvas de nematódeos em pastagens de aveia e azevém com diferentes ofertas de forragem. Dois parâmetros foram avaliados: infecção parasitária de borregas Suffolk em pastejo e contaminação da pastagem por larvas de parasitos de ovinos.

\section{MATERIAL E MÉTODOS}

O experimento foi realizado no Laboratório de Produção de Ovinos e Caprinos (LAPOC) da Fazenda Experimental da Universidade Federal do Paraná, situada no município de Pinhais, PR, latitude $25^{\circ} 25^{\prime}$ Sul, longitude $49^{\circ} 8^{\prime}$ 'Oeste e $915 \mathrm{~m}$ de altitude. O clima na região é classificado como temperado do tipo $\mathrm{Cfb}$, com temperaturas médias no mês mais frio inferiores a $18^{\circ} \mathrm{C}$ e, no mês mais quente, abaixo de $22^{\circ} \mathrm{C}$ (KÖEPPEN, 1928). A precipitação média anual varia de 1400 a $1800 \mathrm{~mm}$ com chuvas bem distribuídas durante o ano.

As forrageiras utilizadas no experimento de inverno foram aveia preta (Avena strigosa) e azevém (Lolium multiflorum). A área experimental foi composta por quatro piquetes, dois com $1900 \mathrm{~m}^{2}$, que corresponderam aos tratamentos de menor oferta de forragem, e os outros dois piquetes com $4100 \mathrm{~m}^{2}$ para os tratamentos que possuíam maior oferta. As forrageiras foram plantadas na quantidade de $80 \mathrm{~kg}$ de semente de aveia por hectare e $30 \mathrm{~kg}$ de semente de azevém por hectare, nos meses de maio e abril, respectivamente. A área experimental foi delimitada por cerca eletrificada e adubada com uréia na 
quantidade de $150 \mathrm{~kg}$ de nitrogênio por hectare. Por se tratar de área de reserva ambiental (APA do rio Iraí), o uso de herbicidas é proibido; assim, o controle de plantas invasoras nos piquetes foi realizado manualmente.

O delineamento utilizado foi inteiramente casualizado em esquema fatorial, com quatro tratamentos compostos por duas ofertas de matéria seca para as duas espécies forrageiras, totalizando quatro tratamentos assim identificados: aveia com oferta de 5\% do peso vivo dos animais (AV 5\%); aveia com oferta de $12 \%$ do peso vivo dos animais (AV 12\%); azevém com oferta de $10 \%$ do peso vivo dos animais (AZ 10\%); azevém com oferta de $20 \%$ do peso vivo dos animais (AZ 20\%).

A massa de forragem foi quantificada quinzenalmente por meio do método do disco (CASTLE, 1976) com 200 aferições por área experimental. Foi mantida carga fixa de sete animais por área experimental e, para se ajustar a massa de forragem por animal, alterou-se o tamanho da área de acordo com a necessidade.

Os animais utilizados como traçadores foram 28 borregas da raça Suffolk com idades entre oito e nove meses, com sete animais para cada tratamento. Antes do início do experimento, os animais passaram por período de adaptação às pastagens, avaliação sanitária geral e receberam dose de vermífugo previamente testado com o objetivo de apresentarem uma carga parasitária baixa nesse momento. Os animais permaneceram em pastejo no período das oito horas da manhã até às quatro horas da tarde, durante todos os dias do experimento.

As amostras das forrageiras destinadas à avaliação da quantidade de larvas presente foram coletadas por meio de um quadro com área de $0,0625 \mathrm{~m}^{2}(25 \times 25 \mathrm{~cm})$, cortadas rente ao solo e devidamente acondicionadas para processamento no Laboratório de Parasitologia Veterinária da UFPR de acordo com o método de TAYLOR (1939) e RAYNAULD \& GRUNER (1982). As amostras foram divididas em estrato pastejado e não pastejado. $\mathrm{O}$ estrato pastejado pelos ovinos corresponde a aproximadamente $50 \%$ da porção superior da planta estendida (LACCA et al., 1992). A porção restante do material coletado no campo, que não foi utilizada para a obtenção das larvas, foi seca em estufa a $65^{\circ} \mathrm{C}$ para a obtenção da quantidade de matéria seca das amostras. Após a contagem das larvas, os valores foram convertidos para número de larvas por grama de matéria seca $\left(\mathrm{L} \cdot \mathrm{g} \mathrm{MS}^{-1}\right)$.

Realizou-se o corte de amostras de pasto ao acaso antes da entrada dos animais no experimento e quinzenalmente após sua entrada. Até o final do período experimental foi possível realizar cinco coletas para cada espécie forrageira (Tabela 1). Como a aveia é uma gramínea com desenvolvimento mais precoce, as avaliações nessas áreas começaram uma semana antes em relação ao azevém.

TABELA 1 - Período das avaliações no inverno de 2003

\begin{tabular}{ccc}
\hline $\mathrm{N}^{\circ}$ da coleta & $\begin{array}{c}\text { Avaliações na } \\
\text { aveia }\end{array}$ & $\begin{array}{c}\text { Avaliações no } \\
\text { azevém }\end{array}$ \\
\hline 1 & $12 / 07 / 2003^{*}$ & $19 / 07 / 2003^{*}$ \\
2 & $26 / 07 / 2003$ & $02 / 08 / 2003$ \\
3 & $09 / 08 / 2003$ & $16 / 08 / 2003$ \\
4 & $23 / 08 / 2003$ & $01 / 09 / 2003$ \\
5 & $06 / 09 / 2003^{* *}$ & $13 / 09 / 2003^{* *}$ \\
\hline
\end{tabular}

* Entrada dos animais na área experimental

** Saída dos animais da área experimental

Para cada tratamento foram realizados quatro cortes de pastagens. As coletas foram realizadas nas horas mais amenas da manhã (das 7 h30 às 10 horas).

As larvas recuperadas da pastagem, após sua contagem, foram agrupadas em uma amostra, por tratamento, estrato e coleta, e identificadas em gêneros conforme a chave de UENO \& GONÇALVES (1994), VAN WYK et al. (2004) e GIBBONS et al. (2005).

Foram realizados exames coproparasitológicos quinzenalmente pelo Método de GORDON-WHITLOCK (1939) modificado e WILLIS (1927). O número de ovos de helmintos por grama de fezes está altamente correlacionado com a contagem de parasitos adultos presentes no trato gastrintestinal do hospedeiro (DOUCH et al., 1996).

O critério para tratamento dos animais ocorreu conforme contagem individual de OPG. Cada vez que esse valor atingiu 500, administrou-se medicação anti-helmíntica com os seguintes princípios ativos: nitroxinil $10,2 \quad \mathrm{mg} / \mathrm{kg} \quad$ e moxidectina $0,2 \mathrm{mg} / \mathrm{kg}$ na forma injetável.

A cultura das larvas de tricostrongilídeos nas fezes foi realizada segundo o método de ROBERTS 
\& O'SULLIVAN (1950) e foi realizada a partir de amostras de fezes dos animais presentes em um mesmo tratamento. A identificação foi realizada conforme a chave proposta por UENO \& GONÇALVES (1994), VAN WYK et al. (2004) e GIBBONS et al. (2005).

As datas de avaliações coproparasitológicas nos animais foram as mesmas das avaliações na pastagem (Tabela 1).

Para análise de variância dos valores encontrados entre os tratamentos foi utilizado o programa Statistica V (STATISTICA, 1995). As médias do número de larvas encontradas entre os tratamentos foram comparadas pelo teste de Duncan a 5\% de significância. Para comparação das médias de ovos de helminto por grama de fezes (OPG) entre os tratamentos, os dados foram transformados em log $(x+1)$ e submetidos ao teste de Duncan a $5 \%$ de significância. $\mathrm{O}$ número de desverminações dos animais foi avaliado pelo teste de resíduos padronizados (teste z para proporções).

\section{RESULTADOS E DISCUSSÃO}

Verificou-se diferença estatística na quantidade de larvas de helmintos por grama de matéria seca $\left(\mathrm{L} . \mathrm{g} \mathrm{MS}{ }^{-1}\right)$ presente na planta inteira $(\mathrm{p}<0,05)$ entre as forrageiras estudadas. A média correspondeu a $24,60 \mathrm{~L} . \mathrm{g} \mathrm{MS}^{-1}$ para aveia e 104,53 L.g $\mathrm{MS}^{-1}$ para azevém. Esses valores estão abaixo do encontrado por DITTRICH et al. (2004) em pastagem de aveia (49,39 L.g $\left.\mathrm{MS}^{-1}\right)$, utilizando metodologia semelhante. Todavia, os referidos autores trabalharam com contaminação artificial de 2 x $10^{6}$ de ovos de nematódeos de ovinos por metro quadrado. Para a pastagem de azevém, encontraram 76,11 L.g MS ${ }^{-1}$.

As coletas foram realizadas considerando-se o conceito de movimentação vertical das larvas (fototropismo), descrito por CAMUSET (1994), nos períodos em que, segundo o autor, haveria maior movimentação vertical das larvas para as porções superiores das plantas (fototropismo negativo).

A maior quantidade de larvas de nematódeos por grama de matéria seca encontradas no azevém, em relação à aveia, foi previamente relatada por DITTRICH et al. (2004), o que corrobora com o presente resultado, provavelmente, por formar um microambiente mais propenso para o desenvolvimento dos ovos de parasitos presentes nas fezes dos animais. O microclima favorável seria proporcionado pela maior densidade de folhas por metro quadrado nessa planta. Dessa maneira, há menor penetração de raios solares devido ao sombreamento ocasionado pelas folhas, o que reduziria a dessecação de ovos e larvas dos parasitos presentes no ambiente.

Entre as espécies forrageiras, observou-se que os tratamentos com azevém apresentaram maior contaminação da pastagem por larvas de helmintos.

No tratamento aveia com $12 \%$ de oferta, verificou-se menor contaminação da pastagem por larvas com relação aos demais (Tabela 2), o que indica que essa forrageira, fornecida em quantidades adequadas, pode ser uma alternativa viável para diminuir o contato dos ovinos com as larvas infectantes de helmintos parasitos.

A contaminação da pastagem por larvas de helmintos nos tratamentos de menor oferta de forragem foi superior $(p<0,05)$ à contaminação dos tratamentos com maior oferta de forragem para as duas espécies forrageiras estudadas (Tabela 2). Dessa forma, quanto maior a lotação da pastagem, maior será a contaminação do piquete e, consequentemente, haverá aumento potencial de reinfecção dos animais.

TABELA 2 - Média do número de larvas de helmintos nos diferentes tratamentos durante 0 inverno por grama de matéria seca (L.g MS $\left.{ }^{-1}\right)$

\begin{tabular}{cc}
\hline Tratamento & L.g MS \\
\hline AVEIA 5\% & $32,81 \mathrm{a}$ \\
AVEIA 12\% & $16,39 \mathrm{~b}$ \\
AZEVÉM 10\% & $139,29 \mathrm{c}$ \\
AZEVÉM 20\% & $69,77 \mathrm{~d}$ \\
\hline
\end{tabular}

As médias na coluna acompanhadas de letras diferentes diferem entre si $(\mathrm{p}<0.05)$, pelo teste de Duncan.

O número de larvas de helmintos por grama de matéria seca $\left(\mathrm{L} . \mathrm{g} \mathrm{MS}^{-1}\right)$ entre os estratos inferior e superior apresentou diferença $(p<0,05)$ tanto para aveia como para azevém. $\mathrm{O}$ estrato inferior apresentou, em ambas as forrageiras, contaminação maior quando comparado ao estrato superior da planta (Tabela 3). Com relação às espécies forrageiras, no azevém ocorreu maior contaminação por larvas do que na aveia em ambos os estratos (inferior e superior), seguindo o mesmo padrão 
observado para a planta inteira. $\mathrm{O}$ trabalhos realizados por DITTRICH et al. (2004) e GAZDA et al. (2009) confirmam que no estrato inferior da planta ocorre maior concentração de larvas. Em estudos realizados com diferentes espécies forrageiras, observou-se diferença no número de larvas encontradas na planta, tanto para forrageiras tropicais, como para forrageiras temperadas (DITTRICH et al., 2004; GAZDA et al., 2009).

Em estudo sobre a quantidade de larvas de nematódeos em diferentes pastagens de verão, GAZDA et al. (2009) observaram valores semelhantes ( $>>0,05)$ para pensacola (Paspalum saurae) e aruana (Panicum maximum). No entanto, observou-se uma maior contaminação por larvas de nematódeos na pastagem $(\mathrm{p}<0,05)$ nos tratamentos de menor oferta de forragem em relação aos de maior oferta, para ambas forrageiras estudadas.

TABELA 3 - Média de larvas de helmintos encontradas no estrato inferior e superior das forrageiras de inverno por grama de matéria seca $\left(\mathrm{L} . \mathrm{g} \mathrm{MS}{ }^{-1}\right)$

\begin{tabular}{ccc}
\hline $\begin{array}{c}\text { Espécie } \\
\text { Forrageira }\end{array}$ & $\begin{array}{c}\text { L.g MS }^{-1} \text { no } \\
\text { estrato inferior }\end{array}$ & $\begin{array}{c}\text { L.g MS } \\
\text { estrato superior }\end{array}$ \\
\hline Aveia & 16,01 a A & $8,60 \mathrm{~b} \mathrm{~A}$ \\
Azevém & 71,17 a B & $33,36 \mathrm{~b} \mathrm{~B}$ \\
\hline
\end{tabular}

Médias seguidas de letras minúsculas diferentes na mesma linha e de letras maiúsculas diferentes na mesma coluna diferem $(\mathrm{P}<0,05)$ pelo teste de Duncan.

No tratamento de aveia com $5 \%$ de oferta de forragem (AV 5\%) o número de larvas de helmintos no estrato inferior e superior foi semelhante (p>0,05), com médias de 18,42 e 14,40 L.g MS ${ }^{-1}$, respectivamente. Para os demais tratamentos, aveia $12 \%$ de oferta e azevém $10 \%$ e $20 \%$ de oferta de forragem, o valor do número de larvas de helmintos por grama de matéria seca foi menor $(\mathrm{p}<0,05)$ no estrato superior em relação ao estrato inferior (Tabela 4).

\section{CALLINAN \& WESTCOTT (1986)}

encontraram maior concentração de larvas no solo e nas plantas até dois centímetros da superfície, o que corrobora com os resultados do presente trabalho. Esses dados comprovam o potencial de maior ingestão de larvas infectantes presentes nas plantas de menor altura e, portanto, em situações de menor oferta de forragem, visto que os ovinos removem aproximadamente 50\% de uma planta estendida (LACA et al., 1992; GALLI et al., 1996). Nos tratamentos com menor oferta de forragem, AV $5 \%$ e AZ $10 \%$, a maior contaminação por larvas de nematódeos foi no estrato superior quando comparados aos tratamentos de maior oferta de forragem, $\mathrm{AV} 12 \%$ e $\mathrm{AZ} 20 \%$, o que demonstra que a adequada oferta de forragem é de fundamental importância na criação de ovinos a pasto (Tabela 4). DITTRICH et al. (2004), em estudo sobre a contaminação de pastagens de aveia e azevém por larvas infectantes de helmintos em diferentes alturas, observaram que as pastagens de menor altura apresentaram maior quantidade de larvas no estrato superior quando comparadas às pastagens de maior altura, o que disponibilizaria aos animais uma maior ingestão de larvas.

Com relação ao estrato inferior, observou-se que, nos tratamentos de aveia, a contaminação da pastagem foi semelhante ( $>0,05)$, enquanto que para o azevém foi maior o número de larvas de nematódeos por grama de matéria seca $(\mathrm{p}<0,05)$ no tratamento com menor oferta (AZ 10\%) em relação ao tratamento de maior oferta (AZ 20\%) (Tabela 4).

Entre as espécies forrageiras observou-se que, no estrato superior dos tratamentos $\mathrm{AV} 5 \%$ (14,40 L.g M.S. $\left.{ }^{-1}\right)$ e AZ 20\% (19,39 L.g M.S. $\left.{ }^{-1}\right)$, não houve diferença $(p>0,05)$ para contaminação de larvas. Para os demais tratamentos, azevém apresentou contaminação maior da pastagem $(p<0,05)$, independente do estrato avaliado.

TABELA 4 - Médias do número de larvas de helmintos por grama de matéria seca nos diferentes tratamentos e respectivos estratos

\begin{tabular}{ccc}
\hline Tratamento & $\begin{array}{c}\text { Larvas/g M.S. } \\
\text { no estrato } \\
\text { inferior }\end{array}$ & $\begin{array}{c}\text { Larvas/g M.S. } \\
\text { no estrato } \\
\text { superior }\end{array}$ \\
\hline AVEIA 5\% & 18,42 a A & 14,40 a A \\
AVEIA 12\% & 13,60 a A & $2,80 \mathrm{~b} \mathrm{~B}$ \\
AZEVÉM 10\% & 91,95 a B & 47,34 b C \\
AZEVÉM 20\% & 50,38 a C & 19,39 b A
\end{tabular}

Médias seguidas de letras minúsculas diferentes na mesma linha e de letras maiúsculas diferentes na mesma coluna diferem $(\mathrm{P}<0,05)$ pelo teste de Duncan.

Ao longo do período experimental houve aumento linear no número de larvas de helmintos por grama de matéria seca no estrato pastejado (superior), no tratamento de aveia com 5\% de oferta 
de forragem (Figura 1). A alta carga animal desse tratamento acarretou a contaminação constante da pastagem com ovos de helmintos.

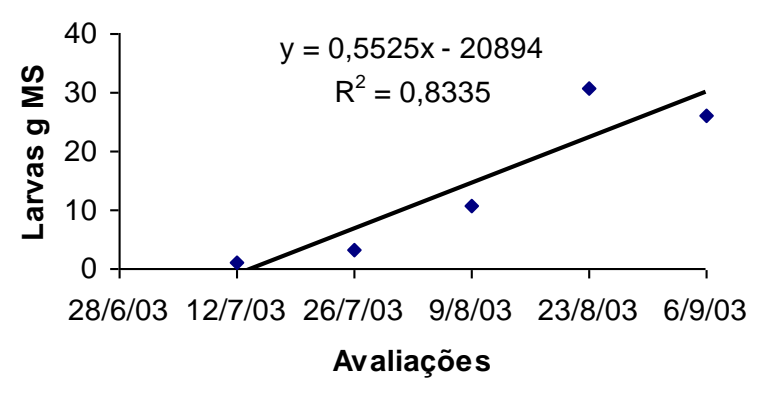

FIGURA 1 - Número de larvas de helmintos por grama de M.S. no estrato pastejado (superior) no decorrer do experimento - tratamento aveia $5 \%$.

Dentre as larvas de nematódeos recuperadas da pastagem de aveia foram identificados os gêneros de tricostrongilídeos de ovinos nas seguintes porcentagens: Trichostrongylus 39,5\%, equivalente a 9,7 larvas infectantes por grama de matéria seca; Haemonchus $4,5 \%$ ou 1,1 larva/g M.S.; e Cooperia $3,3 \%$ ou 0,8 larva/g M.S. As demais larvas de helmintos recuperadas foram Strongyloides 33,9\%, nematódeos de vida livre $16,1 \%$, Muellerius $2,2 \%$ e Bunostomun 0,2\%.

$\mathrm{Na}$ pastagem de azevém foram recuperadas e identificadas larvas dos seguintes gêneros de tricostrongilídeos: Trichostrongylus 44,6\% ou 46,7 larvas/g M.S.; Haemonchus 12,2\% ou 12,8 larvas/g M. S.; e Cooperia 1,5\% ou 1,6 larvas/g M. S. Foram recuperadas larvas dos nematódeos Strongyloides $19,9 \%$, vida livre $17,6 \%$, Muellerius $3,2 \%$, Dictyocaulus 0,7\% e Bunostomun 0,2\%.

Comparativamente, a espécie forrageira azevém apresentou quantidade de larvas do gênero Haemonchus superior ao número de larvas presentes na aveia.

Como o método qualitativo é mais sensível que o quantitativo, amostras com OPG negativo, mas positivas no método de WILLIS (1927), foram consideradas com 100 OPG.

Considerando o grau de infecção parasitária dos animais mantidos nas duas diferentes espécies forrageiras de inverno, não houve diferença quanto ao número de ovos de helmintos por grama de fezes (OPG). A média correspondeu a 677 OPG para os animais que estavam nos piquetes de aveia (AV 5\% e AV 12\%) e 921 OPG para os animais pertencentes aos piquetes de azevém (AZ 10\% e AZ 20\%).

Não foi observada diferença $(p>0,05)$ em relação ao OPG (Tabela 5) entre os animais mantidos nas diferentes ofertas de forragem. Todavia, na pastagem de aveia com oferta de $12 \%$ (AV 12\%) verificou-se média de OPG 50\% inferior ao valor de OPG das demais ofertas de forragem. O tratamento AV $12 \%$ apresentou OPG abaixo de 500, o que sugere menor utilização de medicação antihelmíntica, economia de recursos para os produtores, além da redução do uso de fármacos no sistema de produção.

TABELA 5 - Média de ovos de tricostrongilídeos por grama de fezes (OPG) dos animais nos diferentes tratamentos em pastagem de inverno

\begin{tabular}{cl}
\hline Espécie Forrageira & OPG \\
\hline AVEIA 5\% & $899 \mathrm{a}$ \\
AVEIA 12\% & $466 \mathrm{a}$ \\
AZEVÉM 10\% & $960 \mathrm{a}$ \\
AZEVÉM 20\% & $883 \mathrm{a}$ \\
\hline
\end{tabular}

As médias na coluna acompanhadas de letras diferentes diferem entre si $(\mathrm{p}<0.05)$, pelo teste de Duncan.

O maior número de larvas de helmintos encontradas no azevém, a princípio, não se traduziu em maior carga parasitária dos animais que o pastejaram em relação aos animais pertencentes aos piquetes de aveia. Acredita-se que esse aspecto seja consequência de os dois tratamentos do azevém terem apresentado oferta de forragem alta, de $10 \%$ e $20 \%$ do peso dos animais, o que teria reduzido o possível efeito na carga parasitária dos animais, ocasionado pela espécie forrageira.

Observou-se que no tratamento AV 5\%, que proporcionou a menor oferta de forragem para os animais, houve aumento linear no número de ovos de helmintos por grama de fezes dos animais com o tempo (Figura 2), o que não foi observado para os demais tratamentos com oferta elevada. Coincidentemente, houve o mesmo comportamento para a contaminação da pastagem (Figura 1), o que demonstra que pastagens com altas taxas de lotação levam a um ciclo vicioso: à medida que os animais infectam-se ao ingerir larvas de helmintos parasitas, em decorrência da alta lotação, ocorre recontaminação da pastagem de maneira mais intensa, expondo os animais a uma maior quantidade de larvas e levando a uma consequente reinfecção dos animais que, por sua vez, acumulam carga 
parasitária ainda maior, com agravamento do estado sanitário do rebanho e inviabilização da criação de ovinos a pasto.

GAZDA et al. (2009), em estudo com forrageiras de verão, observaram que animais de tratamentos de menor oferta de forragem apresentaram valores maiores de OPG $(\mathrm{p}<0,05)$, em comparação aos animais de tratamentos de maior oferta de forragem.

Os ovinos mantidos em pastagens das espécies forrageiras aveia e azevém requerem controle parasitológico intensivo, pois, neste estudo, em condições de contaminação natural, constatou-se nas gramíneas a presença considerável de larvas de nematódeos patogênicos, especialmente no azevém.

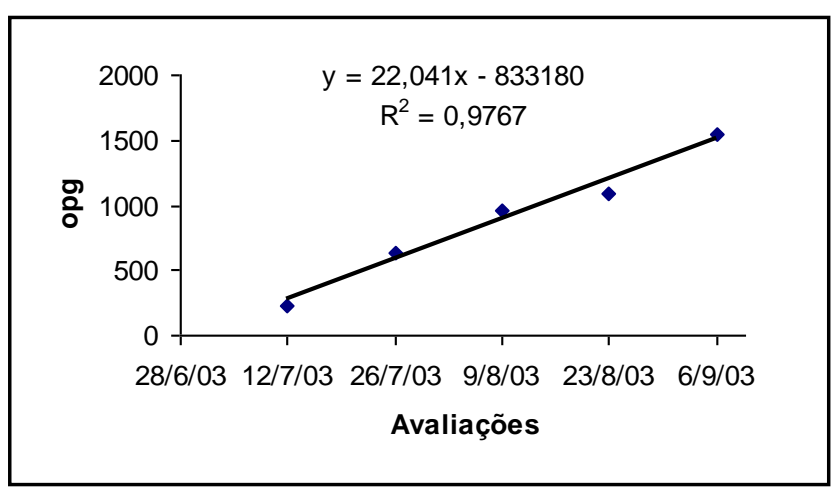

FIGURA 2 - Média de ovos de tricostrongilídeos por grama de fezes (OPG) dos animais do tratamento aveia 5\% ao longo do período experimental.

Na Tabela 6 observa-se o número de animais desverminados isoladamente em cada tratamento. Não foi verificada diferença $(p>0,05)$ no número de desverminações dos animais entre as diferentes ofertas de forragem de aveia e azevém.

TABELA 6 - Número de desverminações por tratamento ao longo do experimento.

\begin{tabular}{cc}
\hline Espécie forrageira & $\begin{array}{c}\text { Número de } \\
\text { desverminações durante o } \\
\text { período experimental }\end{array}$ \\
\hline AVEIA 5\% & $15 \mathrm{a}$ \\
AVEIA 12\% & $11 \mathrm{a}$ \\
AZEVÉM 10\% & $9 \mathrm{a}$ \\
AZEVÉM 20\% & $11 \mathrm{a}$ \\
\hline
\end{tabular}

As médias nas linhas acompanhadas de letras diferentes diferem entre si $(\mathrm{p}<0.05)$, pelo teste de Duncan.

Os valores de ovos de helmintos por grama de fezes não diferiram entre si ( $p>0,05)$; entretanto, considerando-se a epidemiologia da verminose ovina, tais valores contribuíram para a recontaminação do ambiente e causaram o incremento do custo de produção devido ao gasto com as necessárias desverminações dos animais.

No estudo de GAZDA et al. (2009) foi constatado que animais mantidos em maior oferta de forragem apresentaram menor número $(\mathrm{p}<0,05)$ de desverminações individuais em relação aos tratamentos de menor oferta de forragem.

Durante o período de avaliação, as coproculturas indicaram prevalência do gênero Trichostrongylus $(40,1 \%)$ sobre os gêneros Haemonchus (29,9\%), Cooperia (20,2\%) e Strongyloides $(9,8 \%)$.

\section{CONCLUSÕES}

A quantidade superior de larvas nas pastagens com menor oferta de forragem juntamente com a maior quantidade de larvas observadas no estrato superior desses tratamentos indicam que a adequada oferta de forragem pode ser utilizada como estratégia de controle da verminose ovina, com a redução do contato do ovino com o parasito.

A alta carga animal por unidade de área contribuiu para a contaminação constante da pastagem e, consequentemente, para a infecção dos animais.

\section{REFERÊNCIAS}

CALLINAN, A. P. L.; WESTCOTT, J. M. Vertical distribution of Trichostrongylid larvae on herbage and in soil. International Journal for Parasitology, v.16, n.3, p.241- 244, 1986.

CAMUSET. Epidemiologie des strongyloses, Parasitisme des bovins, Bulletin dês GTV, n.e, 27-42, 1994.

CASTLE, M. E. A simple disc instrument for estimating herbage yield. Journal of the British Grassland Society, 1976, c.31, p. 37-40, 1976.

CASTRO, A. A.; ALMEIDA, L. R.; SILVA, F. J. M.; GUEDES JÚNIOR, D. S.; OLIVEIRA, C. J. F.; ORNELAS, E. I.; FONSECA, A. H. Comparação entre as técnicas de Baermann modificada e Donald utilizadas para recuperar larvas infectantes de nematóides gastrintestinais de ruminantes da pastagem. Revista Brasileira de Parasitologia Veterinária, v.12, n.2, p.88-91, 2003.

DITTRICH, J. R.; GAZDA, T. L.; PIAZZETTA, R. G.; OIKAWA, M. G.; RODRIGUES, C. S.; THOMAZ- 
SOCCOL, V. Localização de Larvas L3 de helmintos gastrintestinais de ovinos nas plantas forrageiras: Efeito da espécie vegetal e altura. Archives of Veterinary Science. v.6, n.2, p.43-48, 2004.

DOUCH, P.G.C.; GREEN, R.S.; MORRIS, C.A.; McEWANS, J.C.; WINDON, R.G. Phenotypic markers for selection of nematode-resistant sheep. International Journal for Parasitology, v. 26, n.8/9, p. 899-911,1996.

GAZDA, T. L.; PIAZZETTA, R. G.; DITTRICH， J. R.; MONTEIRO, A. L. G.; SOCCOL, V. T. Distribution of nematode larvae of sheep in tropical pasture plants. Small Ruminant Research, v. 82, p. 94-98, 2009.

GIBBONS, L. M.; JACOBS, D. E.; FOX, M. T.; HANSEN, J. The Royal Veterinary College and Food and Agriculture Organization of the United Nations guide to veterinary diagnostic parasitology. 2005 Disponível em: http://www.fao.org/ag/againfo/resources/it/multimedia.ht ml. Acesso em 06 de março de 2008.

GORDON, H. McL.; WHITLOCK, H. V. A new technique for counting nematode eggs in sheep faeces. Journal of the Council for Scientific and Industrial Research, v. 12, p. 50, 1939.

KÖEPPEN, W. Klimakarte der erde. Gotha, Perthes. 1928.

LACA, E. A.; UNGAR, E. D.; SELIGMAN, N. G.; DEMMENT, M. W. Effects of sward height and bulk density on the bite dimensions of cattle grazing homogeneous sward. Grass and Forage Science, v.47, n. 2, p. 91- 102, 1992.

MORAES, A.; MARASCHIN, G .E. Pressões de pastejo e produção animal em milheto comum. Pesquisa Agropecuária Brasileira, n.23, v.2, p.197-205, 1988.

NIEZEN, J. H.; CHARLESTON, W. A. G.; HODGSON, J.; MILLER, C. M.; WAGHORN, T. S.; ROBERTSON, H. A. Effect of plant species on the larvae of gastrointestinal nematodes which parasitise sheep. International Journal for Parasitology, v. 28, n. 5, p. 791-803, 1998a.

NIEZEN, J. H.; ROBERTSON, H. A.; WAGHORN, G.
C.; CHARLESTON, W. A. G. Production, faecal egg counts and worm burdens of ewes lambs which grazed six contrasting forages. Veterinary Parasitology, v. 80, p. $15-27,1998 b$.

RAYNAULD, J. P.; GRUNER, L. Feasibility of herbage sampling in large extensive pastures and availability of cattle nematode infective larvae in mountain pastures, Veterinary Parasitology, Amsterdam, v. 10, p. 57-64, 1982.

ROBERTS, F. H. S.; O'SULLIVAN, P. J. Methods for egg counts and larval cultures for strongyles infecting the gastro-intestinal tract of cattle. Australian Journal of Agriculture Research, Collingwood, v. 1, p. 99, 1950.

STATISTICA for Windows: release 5.0 A. Tulsa: Statsoft Inc., 1995.

TAYLOR, E. L. Technique for the estimation of pastures infestation by strongyle larvae. Parasitology, v. 31, p. 473-478,1939.

THOMAZ-SOCCOL, V.; SOTOMAIOR, C.; SOUZA, F. P.; CASTRO, E. A.; PESSÔA SILVA, M. C.; MILCZEWSKI, V. Occurence of resistance to antihelmintics in sheep in Paraná State, Brazil. Veterinary Record, London, v. 139, p. 421-422, 1996.

THOMAZ-SOCCOL, V.; SOUZA, F. P.; SOTOMAIOR, C.; CASTRO, E. A.; MILCZEWSKI, V.; MOCELIN, G.; PESSÔA SILVA, M. C. Resistance of gastrointestinal nematoda to antihelmintics in sheep (Ovis aries). Brazilian Archives of Biology and Technology. v. 47, n.1, p. 41-47, 2004.

UENO, H.; GONÇALVES, P. C. Manual para diagnóstico das helmintoses de ruminantes. 3. ed. Tóquio, 1994. 84 p.

VAN WYK, J. A.; CABARET, J.; MICHAEL, L. M. Morphological identification of nematode larvae of small ruminants and cattle simplified. Veterinary Parasitology. v.119, p.277-306, 2004.

WILLIS, H. H. A simple levitation method for the detection of hookworm ova. Medical Journal of Australia, v. 8, p. 375-376, 1927. 